\title{
The patients' opinion on the use of information technologies at the Šeškinè Outpatient Clinic and "Centro poliklinika" Outpatient Clinic of the city of Vilnius according to the age of patients
} \author{
Rolandas Cepulis ${ }^{1}$ \\ ${ }^{1}$ Faculty of Medicine, Vilnius University, Vilnius, Lithuania; ${ }^{\#}$ Corresponding Author: kajo@ktl.mii.lt \\ ${ }^{2}$ Šeškinè Outpatient Clinic, Vilnius, Lithuania \\ 3“Centro poliklinika" Outpatient Clinic, Vilnius, Lithuania \\ ${ }^{4}$ Mykolas Romeris University, Vilnius, Lithuania \\ ${ }^{5}$ Vilnius University Hospital Santariškių Klinikos, Vilnius, Lithuania
}

Jonas Kairys ${ }^{1,2 \#}$, Rimantas Stukas ${ }^{1}$, Rasa Stundžiené ${ }^{1,2}$, Kęstutis Štaras ${ }^{3,4}$, Pranas Šerpytis ${ }^{1,5}$,

Received 24 September 2013; revised 21 November 2013; accepted 1 December 2013

Copyright (C) 2013 Jonas Kairys et al. This is an open access article distributed under the Creative Commons Attribution License, which permits unrestricted use, distribution, and reproduction in any medium, provided the original work is properly cited.

\begin{abstract}
Objectives: The objective of this study is to assess patients' opinion of the information technologies (IT) electronic registration systems at the "Centro poliklinika" and Šeškinè outpatient clinics in Vilnius City. Material and Methods: The survey was conducted in May-June, 2012. In the course of the primary survey, one questionnaire was handed out to one in tenth of the newly arrived patients. Total number of 650 questionnaires was distributed. 563 respondents participated in the survey (feedback rate-86.6\%). Statistical analysis of data was performed by means of personal computer using SPSS software package. Results: $54.7 \%$ of respondents state that they make use of the possibility of online registration with the family doctor. $85.05 \%$ of respondents indicate that a doctor, when making the next appointment or referring to the medical specialist, registers a patient on site by means of computer. Upon arrival of a respondent to the reception desk of the medical establishment, $90.3 \%$ of respondents are registered by means of computer. $72.4 \%$ of respondents say that they have a choice to telephone and inquire about the time of visit if they have forgotten the visit time or lost the appointment sheet. Majority of respondents using the online registration option
\end{abstract}

*Statement of Conflict of Interest: The authors state no conflict of interest. belong to the age group between 21 and 40 years-35.3\%. Conclusions: Answers by the respondents and the breakdown between "Centro poliklinika" and Šeškinè outpatient clinics are very similar and no essential differences have been determined.

Keywords: Patients' Opinion; Outpatient Health Care; E-Health; Population Age Groups

\section{INTRODUCTION}

E-health care system development in Lithuania was approved by 22 February 2010 Order "Re Approval of the Programme of the Lithuanian e-Health System Development for 2009-2015" of the Minister of Health of the Republic of Lithuania [1]. Concrete actions for implementation of the Programme were laid down by 18 June 2010 Order "Re Approval of the Roadmap for Implementation of the e-Health System Development Programme for the years 2009-2015" of the Minister of Health of the Republic of Lithuania [2]. These documents set forth national and regional level e-Health projects in Lithuania. The Programme defines the context, measures and actions how to efficiently use information to improve population health and health care. The Lithuanian e-Health system makes influence upon the whole health care scope, ranging from services to management and accounting. It enables to enhance people's awareness and their concern in health, to effectively use available resources in providing health care services, to 
develop new services based upon sophisticated information and communication facilities, to improve service quality, availability and accessibility [1,2]. Other authors also write about e-Health issues, and information technologies. The work has been accomplished in Western India demonstrating that improvement of the quality of work requires motivation of doctors, improvement of patient care, and communication based upon information technologies [3]. Modernization of the existing information programmes, intended for health care, sponsored by the Government is planned in the US. This will be a costly process, however, upgrading information programmes will create conditions for a more efficient work of physicians and hospitals [4]. It is of paramount importance for medical staff to get access to the needed information at libraries. The new Web 2.0 versions, currently being developed and implemented, allows to speed up this process [5]. Analyses are made as to which communication network is more rational and cheaper-telephone or Internet based [6]. Also, advantage of mobile applications in the use of health care system is identified - patients and physicians may connect and log in to databases and check up the relevant information at any time [7]. The ways how to improve health care through the use of information technologies have been identified: using them for the dialogue between physicians and administrators, solving different problems using assistance of experts in information technologies, facilitating medical professionals in obtaining knowledge and practice of the new information systems, communicating with other organizations, which require data on the activities of health care facilities [8]. A pilot project of electronic health record has been implemented in three communities in Massachusetts, USA. The authors assume that such project might be pursued state-wide or even on a wider scale [9]. Other European countries, such as Norway, Denmark, Germany, Greece, Poland, Portugal, Latvia also develop e-Health projects [10]. The range of application of such projects is diverse. One of the goals might be the use of the projects for promotion of healthy lifestyle among senior citizens by developing a website for such purpose [11].

We should be proud of the initiative shown by some healthcare facilities of Lithuania aiming at development of their own information systems, which afterwards will be easily integrated into the common core developed by the Ministry of Health. First doctoral theses have been defended in the area of biomedical science, public health and management, investigating the issues related to eHealth $[12,13]$.

Since its foundation in 1987, Šeškinè Outpatient Clinic, a non-profit public health care institution with around 600 employees, has been the largest outpatient clinic, serving most of the population among others out- patient clinics in the country. Until now, it has remained the leading outpatient institution in the health care sector, dynamically adjusting to quickly changing market developments and requirements. The staff gain qualification in courses and scientific conferences both in Lithuania and in other countries. A training base has been functioning in the outpatient clinic for many years. Future medics have an opportunity to gain theoretical and practical knowledge using it. The objective of the outpatient clinic staff- to provide on due time realizable high quality assistance of trained experts - was assessed by conformity certificates LST ISO 9001:2008.

The "Centro poliklinika" together with its' branches at the current moment is the biggest outpatient clinic in Vilnius city, serving about 140,000 inhabitants. The name of the clinics "Centro" also expresses its placeoutpatient clinic is situated in the city centre of Vilnius. The vision of the Clinic is to render the medical and social services of the highest quality. It's the only outpatient clinic in Vilnius, which offers on-duty doctor services, providing public health care services to its patients as well as to patients from other clinics twenty-four hours a day.

The "Centro poliklinika" and Šeškinè outpatient clinics in Vilnius City operate different patients' electronic registration systems, which are intended to provide online registration facilities for patients without having to appear for registration for a visit at the reception desk.

\section{OBJECTIVES AND TASKS OF THE SURVEY}

The objective of this study is to assess patients' opinion of the information technologies (IT) electronic Registration systems at the "Centro poliklinika" and Šeškinè outpatient clinics in Vilnius City. The tasks are to identify whether patients make use of the opportunity of online registration for a visit to general practitioner (family doctor), to describe the procedure of onsite registration at the medical establishment, whether a patient is able to obtain information on the time of his visit from registration systems of the clinics, etc. All the questions given to a patient were benchmarked according to a patient's age.

\section{SCOPE AND METHODOLOGY OF THE SURVEY}

The authors developed a questionnaire for the purpose of the survey including such questions as: How often a patient has visited a healthcare facility over the last two years? Whether a patient takes opportunity of online registration for a visit to a general practitioner? Whether a physician makes registration at the workplace by means of computer or sends a patient to the reception desk at 
the clinic, when making next appointment or referring to a specialist doctor? Whether a patient, upon arrival at the reception desk, is registered by means of computer or in a "paper" format? Can a patient, having forgotten the visit time, make a call to the reception desk and get information on it? Whether a patient gets reply to an electronic letter sent by e-mail to the outpatient clinic? What are the commonest instances when a patient uses Internet? Whether patients use the website of their outpatient clinic and whether they find all the required information there? Are patients willing that information on their health is made available online?

The survey was conducted in May and June, 2012. 100 questionnaires were handed out to one in tenth of the newly arrived patients at the "Centro poliklinika" and Šškine outpatient clinics each. The value of obtained Cronbach's alpha coefficient equalled 0.66 , which confirmed that the questionnaires were suitable for use and did not require adjustment. One questionnaire was handed out to every tenth newly arrived patient during the course of the main survey; total number of the questionnaires distributed being 650. 563 respondents participated in the survey (feedback rate-86.6\%). 407 questionnaires were handed out at the "Centro poliklinika" Outpatient Clinic, and 397 completed questionnaires were received (feedback rate-97.5\%); while at the Šeškinè Outpatient Clinic 243 questionnaires were handed out, with 166 completed ones returned (feedback rate$68.3 \%)$.

Sample of 563 respondents who participated in the survey consisted of 45 males $(27.27 \%)$ and 120 females $(72.73 \%)$ in Šeškinè Outpatient Clinic and 107 males (27.79\%) and 278 (72.21\%) females in "Centro poliklinika" Outpatient Clinic. Out of 163 respondents who indicated their educational level in Šeškinè Outpatient Clinic 77 (46.95\%) had university education, 61 college $(37.19 \%), 22$ were finished secondary school $(13.41 \%)$ and $4(2.43 \%)$ had an elementary education. Out of 393 respondents who indicated their educational level in "Centro poliklinika" Outpatient Clinic 165 indicated university level education (41.98\%), 110 college $(27.98 \%)$, 108 were finished secondary school (27.48\%), 7 (1.78\%) had an elementary school education and $3(0.76 \%)$ indicated that they were not finished elementary school.

While making further analysis of the questionnaires, it was determined that not all respondents answered to all the questions; hence the number of answers might be smaller. In this paper age as the main variable was used, however, further analysis of the questionnaires also covers gender, economic condition (incomes) and education level, which is not so widely covered here because of the extent reasons.

Statistical analysis of data was performed by means of personal computer using SPSS (Statistical Package for the Social Sciences) software package. The differences between respective figures are deemed reliable when error probability is $p \leq 0.05$. When $p>0.05$, it implies that the deviations value according to age groups are not essential.

\section{SURVEY RESULTS}

292 respondents $(54.07 \%)$, out of total number of 540, state that they make use of the opportunity of online registration with the family doctor. At the Šeškinè Outpatient Clinic, the rate is $88(55.0 \%)$ out of 160 respondents, while at the "Centro poliklinika" Outpatient Clinic-204 $(53.7 \%)$ out of 380 respondents. Major part of such respondents fall into the age group of 21 to 40 years (see Table 1).

455 respondents $(85.05 \%)$ out of total 535 of those who responded state that they are registered on site by means of computer for the next appointment with a physician or referral to a medical specialist. At the Šeškinè Outpatient Clinic, 137 respondents $(85.6 \%)$ out of total 160 gave such answer. At the "Centro poliklinika" Outpatient Clinic, such response was received from 318 respondents $(84.8 \%)$ out of total number 375 . No apparent variances according to the age groups at both clinics are manifest (see Table 2).

Majority of respondents-488 (90.3\%) out of total 540 indicate that they are registered by means of computer upon arrival at the reception desk of the healthcare institution. At the Šeškinè Outpatient Clinic, number of those who gave such response was 149 (93.7\%), while at the "Centro poliklinika" Outpatient Clinic 339 (89.0\%). As respondents stated, there were 17 cases of registration in a "paper" format (3.15\%). No apparent variances according to the age groups at both clinics are manifest (see Table 3).

The majority of respondents state that information can be received by phone or accessed online in the event if they forget the date and time of the visit. It is also indicated that reminder notice is given by e-mail or SMS text message sent to the phone. A number of respondents indicated more than one means of obtaining information (see Table 4). A small share of respondents, namely 4 $(0.75 \%)$ out of total 536 of those who gave response, said that the institution was unable to update information on the time of visit and a new registration was required. Part of the respondents did not know how to respondthere being 57 (10.6\%) such respondents. Such respondents mostly belong to the age group of 21 to 40 years35.3\% (see Table 4).

The majority of respondents-242 $(46.3 \%)$ out of total 523 respondents wish to $\log$ in to the online registration system of the outpatient clinic using their personal identification number, which is deemed more convenient. At the Šeškine Outpatient Clinic, number of those who gave 
Table 1. Distribution of respondents when responding to the question whether they make use of online registration for a visit to family doctor (GP).

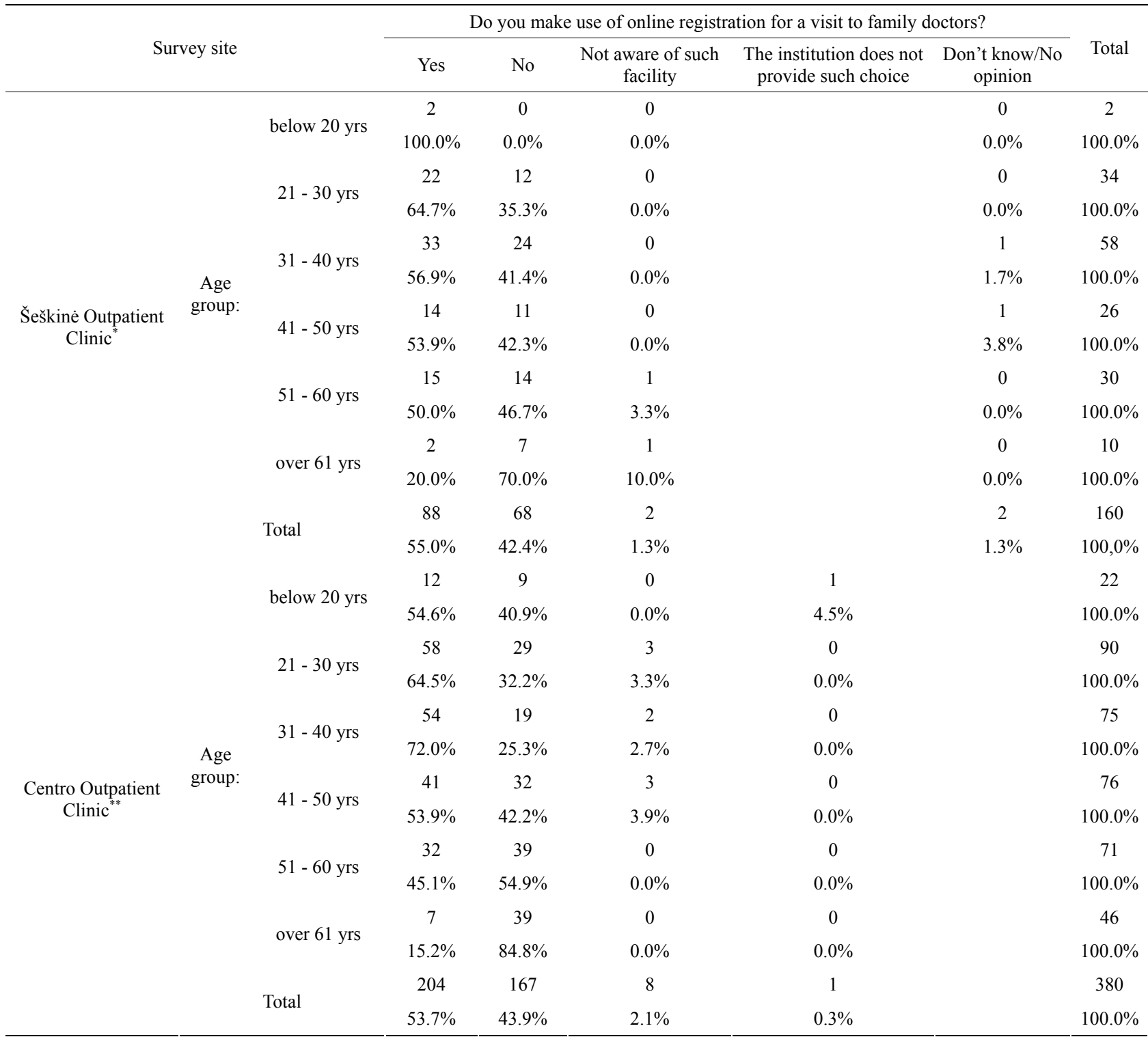

$\chi^{*}=18,034 ; \mathrm{p}=0.261 ;{ }^{* *} \chi^{2}=69,709 ; \mathrm{p}=0.000$

such response was $65(41.7 \%)$ out of total 156 responders. At the "Centro poliklinika" Outpatient Clinic this rate is equal to $177(48.2 \%)$. Part of the respondents$208(39.8 \%)$ out of total of those who responded do not have own opinion whether it is more convenient to log in through the banking system or using one's personal ID number. Distinct variances according to the age groups have not been shown (see Table 5).

The majority of respondents - $242(83.7 \%)$ out of total number 289 of those who responded say that the use of the outpatient clinic website is convenient. At the Šeškinè Outpatient Clinic, 80 respondents $(75.5 \%)$ out of total number 106 are of such opinion, and at the "Centro poliklinika" Outpatient Clinic, 162 respondents (88.5\%) out of total 183. Distinct variances according to the age groups have not been shown (see Table 6).

\section{DISCUSSION OF RESULTS}

A similar study was conducted two years ago, when the opinion of patients on information technologies was also surveyed according to the age groups among the patients of the Šeškine Outpatient Clinic and the "Centro poliklinika" Outpatient Clinic [14]. 292 respondents $(54.07 \%)$ out of total number 540 of those who gave response state that they make use of the opportunity of online registration for a visit to the family doctor (GP). In comparison to the survey carried out in 2010 (14), the 
Table 2. Distribution of respondents when responding to the question on how next appointment is made.

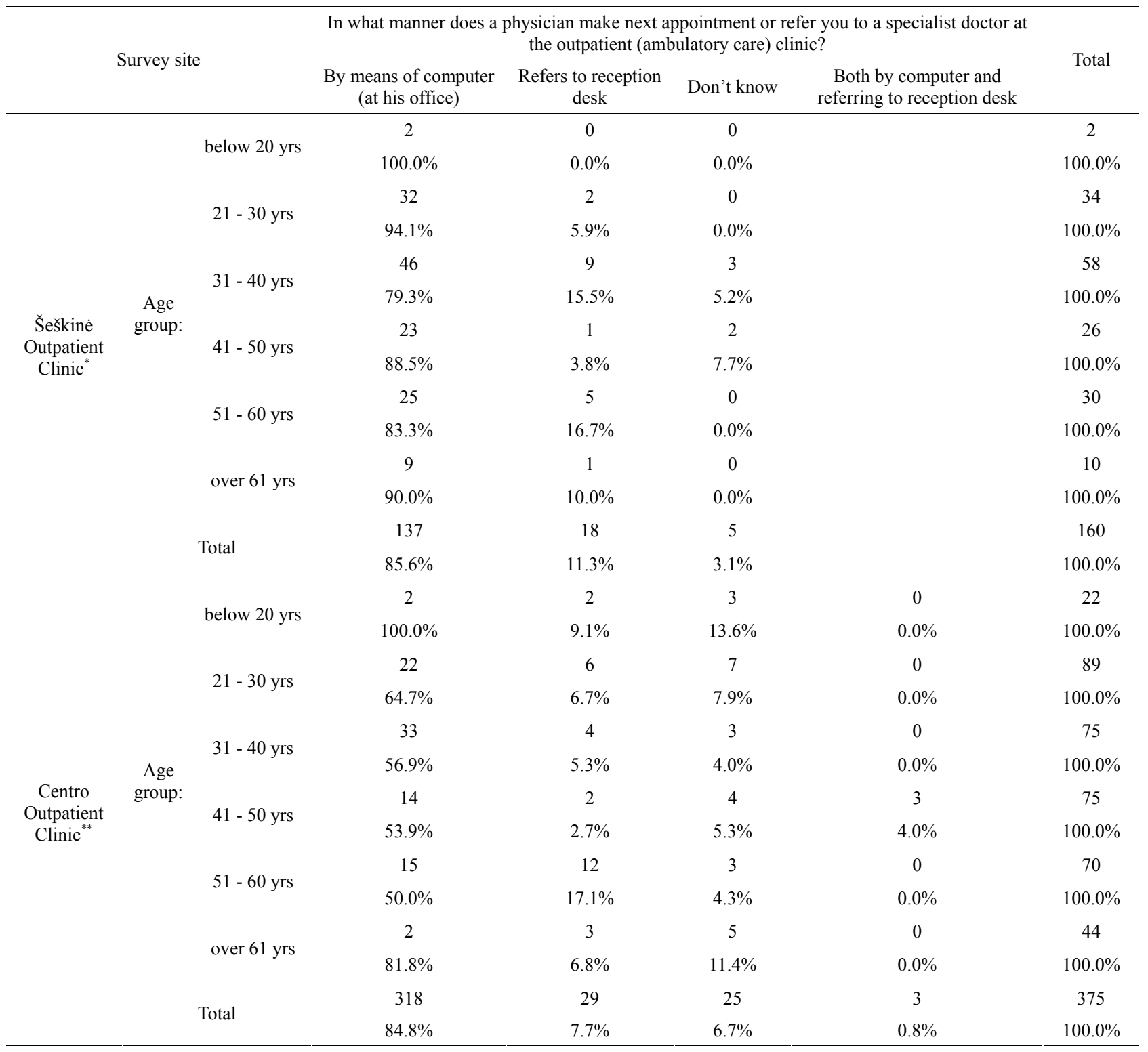

${ }^{*} \chi^{2}=9656 ; \mathrm{p}=0.471 ;{ }^{* *} \chi^{2}=29,034 ; \mathrm{p}=0.016$

percentage of such respondents increased from $45.1 \%$ to $54.07 \%$.

$85.05 \%$ of respondents indicate that registration for the next appointment or referral for consultation of the medical specialist is done on site by means of computer. In comparison to the survey carried out in 2010 (14), the percentage of such respondents increased from $81.8 \%$ to $85.05 \%$. The breakdown according to the age groups is similar at both outpatient clinics.

$90.3 \%$ out of total number 540 of those who answered say that they are registered by means of computer at the reception desk upon arrival at the healthcare facility. In comparison to the survey carried out in 2010 [14], the percentage of such respondents increased from $80.3 \%$ to
$90.3 \%$. The breakdown according the age groups of respondents is rather equal: 21 - 30 year age group$20.6 \% ; 31$ - 40 year age group $-22.6 \% ; 41$ - 50 year age group - $17.4 \%$; 51 - 60 year age group - $17.4 \%$ ). As stated by respondents, registration by the "paper" format was made in 17 instances $(3.15 \%)$.

The majority of respondents (388 out of total number 536 of those who answered) (72.4\%) state that information can be received by phone or accessed online in the event if they forget the date and time of the visit. It is also indicated that reminder notice is given by e-mail or SMS text message sent to the phone. The breakdown according the age groups of respondents is as follows: 21 - 30 year age group—-93 (17.4\%); 31 - 40 year age group 
Table 3. Distribution of respondents when responding to the question on the manner of registration at the reception desk.

\begin{tabular}{|c|c|c|c|c|c|c|}
\hline & \multirow{2}{*}{\multicolumn{2}{|c|}{ Survey site }} & \multicolumn{3}{|c|}{$\begin{array}{l}\text { Upon your arrival at the reception desk of the outpatient (ambulatory care) clinic, your } \\
\text { appointment with a physician is registered }\end{array}$} & \multirow{2}{*}{ Total } \\
\hline & & & By means of computer & "Paper" version & Don't know & \\
\hline \multirow{12}{*}{$\begin{array}{l}\text { Šeškinè } \\
\text { Outpatient } \\
\text { Clinic }^{*}\end{array}$} & \multirow{12}{*}{$\begin{array}{l}\text { Age } \\
\text { group: }\end{array}$} & \multirow{2}{*}{ below 20 yrs } & 2 & 0 & 0 & 2 \\
\hline & & & $100.0 \%$ & $0.0 \%$ & $0.0 \%$ & $100.0 \%$ \\
\hline & & \multirow{2}{*}{$21-30 \mathrm{yrs}$} & 34 & 0 & 0 & 34 \\
\hline & & & $100.0 \%$ & $0.0 \%$ & $0.0 \%$ & $100.0 \%$ \\
\hline & & \multirow{2}{*}{$31-40 \mathrm{yrs}$} & 53 & 0 & 5 & 58 \\
\hline & & & $91.4 \%$ & $0.0 \%$ & $8.6 \%$ & $100.0 \%$ \\
\hline & & \multirow{2}{*}{$41-50 \mathrm{yrs}$} & 23 & 0 & 2 & 25 \\
\hline & & & $92.0 \%$ & $0.0 \%$ & $8.0 \%$ & $100.0 \%$ \\
\hline & & \multirow{2}{*}{$51-60 \mathrm{yrs}$} & 28 & 2 & 0 & 30 \\
\hline & & & $93.3 \%$ & $6.7 \%$ & $0.0 \%$ & $100.0 \%$ \\
\hline & & \multirow{2}{*}{ over 61 yrs } & 9 & 1 & 0 & 10 \\
\hline & & & $90.0 \%$ & $10.0 \%$ & $0.0 \%$ & $100.0 \%$ \\
\hline \multirow{16}{*}{$\begin{array}{l}\text { Centro } \\
\text { Outpatient }^{\text {Clinic }}{ }^{* *}\end{array}$} & \multirow{16}{*}{$\begin{array}{l}\text { Age } \\
\text { group: }\end{array}$} & \multirow{2}{*}{ Total } & 149 & 3 & 7 & 159 \\
\hline & & & $93.7 \%$ & $1.9 \%$ & $4.4 \%$ & $100.0 \%$ \\
\hline & & \multirow{2}{*}{ below $20 \mathrm{yrs}$} & 2 & 2 & 4 & 22 \\
\hline & & & $100.0 \%$ & $9.1 \%$ & $18.2 \%$ & $100.0 \%$ \\
\hline & & \multirow{2}{*}{$21-30 \mathrm{yrs}$} & 22 & 3 & 10 & 90 \\
\hline & & & $64.7 \%$ & $3.3 \%$ & $11.1 \%$ & $100.0 \%$ \\
\hline & & \multirow{2}{*}{$31-40$ yrs } & 33 & 2 & 5 & 76 \\
\hline & & & $56.9 \%$ & $2.6 \%$ & $6.6 \%$ & $100.0 \%$ \\
\hline & & \multirow{2}{*}{$41-50 \mathrm{yrs}$} & 14 & 1 & 4 & 76 \\
\hline & & & $53.9 \%$ & $1.3 \%$ & $5.3 \%$ & $100.0 \%$ \\
\hline & & \multirow{2}{*}{$51-60 \mathrm{yrs}$} & 15 & 4 & 0 & 70 \\
\hline & & & $50.0 \%$ & $5.7 \%$ & $0.0 \%$ & $100.0 \%$ \\
\hline & & \multirow{2}{*}{ over 61 yrs } & 2 & 2 & 5 & 47 \\
\hline & & & $85.1 \%$ & $4.3 \%$ & $10.6 \%$ & $100.0 \%$ \\
\hline & & \multirow{2}{*}{ Total } & 339 & 14 & 28 & 381 \\
\hline & & & $89.0 \%$ & $3.7 \%$ & $7.3 \%$ & $100.0 \%$ \\
\hline
\end{tabular}

${ }^{*} \chi^{2}=16,000 ; p=0.100 ;{ }^{* *} \chi^{2}=16,859 ; p=0.078$.

$-96(17.9 \%) ; 41$ - 50 year age group - 66 (12.3\%); 51 60 year age group $-71(13.2 \%)$. In comparison to the survey carried out in 2010 [14], the percentage of such respondents increased from $64.3 \%$ to $72.47 \%$. A number of respondents indicated more than one means of obtaining information. A small share of respondents, namely 4 $(0.75 \%)$ out of total 536 of those who gave response, said that the institution was unable to update information on the time of visit and a new registration was required. Part of the respondents did not know how to respondthere being $57(10.6 \%)$ such respondents.

The majority of respondents-242 $(46.3 \%)$ out of total 523 respondents wish to $\log$ in to the online registration system of the outpatient clinic using their personal identification number, which is deemed more convenient.
Part of the respondents-208 (39.8\%) out of total of those who responded do not have own opinion whether it is more convenient to log in through the banking system or using one's personal ID number.

The majority of respondents-242 $(83.7 \%)$ out of total number 289 of those who responded say that the use of the outpatient clinic website is convenient. At the Šeškinè Outpatient Clinic, 80 respondents (75.5\%) out of total number 106 are of such opinion, and at the "Centro poliklinika" Outpatient Clinic, 162 respondents (88.5\%) out of total 183 .

When comparing the results of our survey with the data given in the doctoral dissertation of A. Rackauskiene Juodaite [12], it becomes evident that the staff of Vilnius "Centro poliklinika" Outpatient Clinic are satisfied with 
Table 4. Distribution of respondents when responding to the question on how information on the planned visit to a physician is obtained.




Table 5. Distribution of respondents when responding to the question on the desired means of login to the online registration system how information on the planned visit to a physician is obtained.

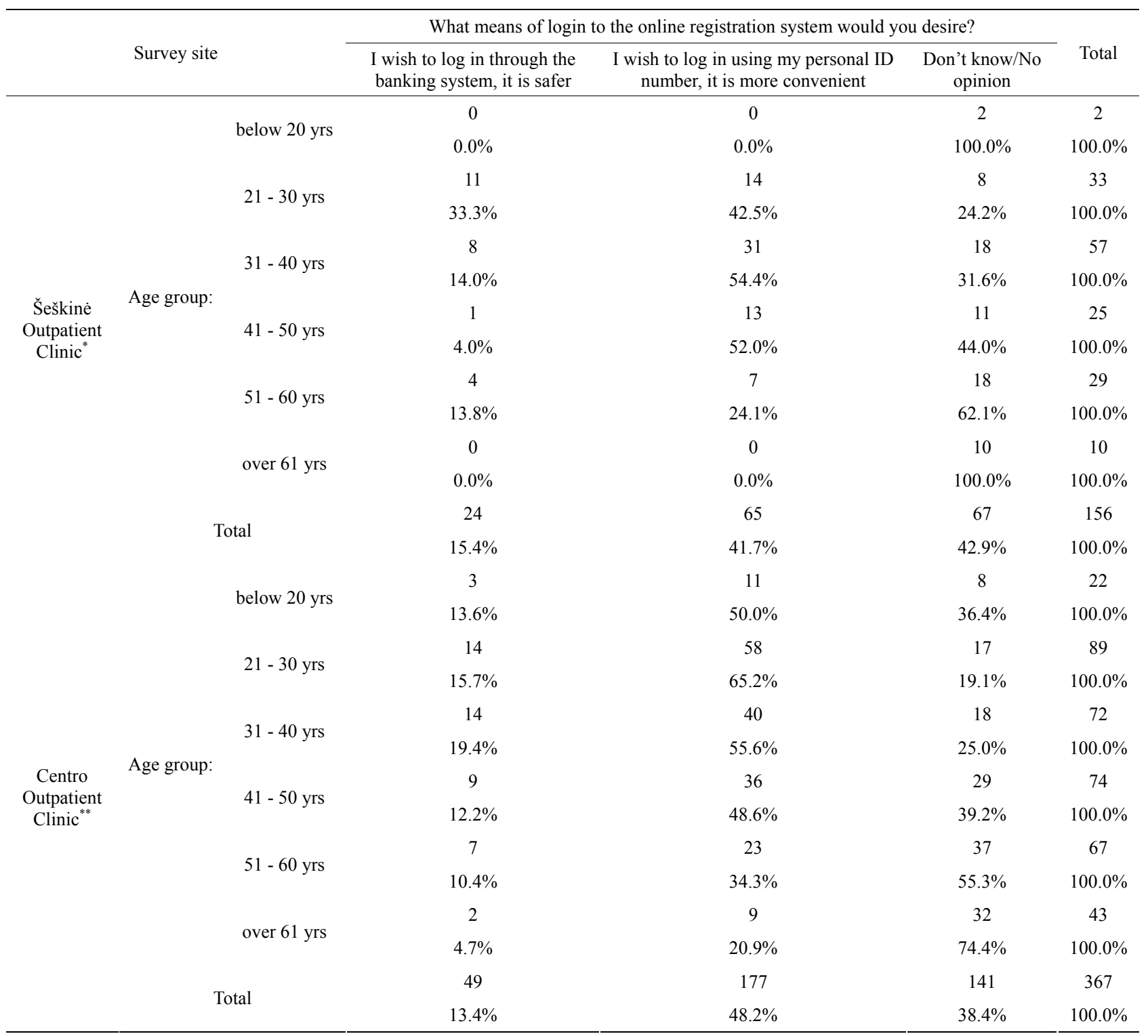

$\chi^{*}=36,948 ; p=0.000 ; \chi^{* *} \chi^{2}=52,247 ; p=0.000$

the changes at their workplace, which is the result of a successful implementation of information systems. The staff sees information systems as an integral part of their job. The staff of Vilnius "Centro poliklinika" Outpatient Clinic have realized the benefits of information technologies and are ready for the further IT implementation at their healthcare facility. The medical information system, while transforming job management of the entire institution, has made a large impact on the work of the reception desk, especially on its operational efficiency and quality.

Information technologies in the healthcare sector, and their efficient application gives unquestionable benefits for the process management at a healthcare facility [13].

\section{CONCLUSIONS}

1) Responses and distribution of the respondents between the Šeškinè Outpatient Clinic and the "Centro poliklinika" Outpatient Clinic are very similar, without any essential differences.

2) $54.7 \%$ of respondents state that they make use of the possibility of online registration with the family doctor (General Practitioner). A larger share of such respondents belongs to the age group of 21 to 40 years.

3) $85.05 \%$ of respondents indicate that a doctor, when making the next appointment or referring to the medical specialist, registers a patient on site by means of computer. No apparent differences in the breakdown accord- 
Table 6. Distribution of respondents when responding to the question whether it is convenient to use the website of their outpatient clinic.

\begin{tabular}{|c|c|c|c|c|c|c|}
\hline & \multirow{2}{*}{\multicolumn{2}{|c|}{ Survey site }} & \multicolumn{3}{|c|}{ Do you find it convenient to use the website of your outpatient clinic? } & \multirow{2}{*}{ Total } \\
\hline & & & $\begin{array}{l}\text { Yes, } \\
\text { convenient }\end{array}$ & $\begin{array}{l}\text { Inconvenient, the website is } \\
\text { extremely intricate }\end{array}$ & $\begin{array}{l}\text { The website is not adapted for the use of mobile } \\
\text { applications (tablet computer, telephone) }\end{array}$ & \\
\hline \multirow{12}{*}{$\begin{array}{l}\text { Šeškinè } \\
\text { Outpatient } \\
\text { Clinic }^{*}\end{array}$} & \multirow{12}{*}{$\begin{array}{l}\text { Age } \\
\text { group: }\end{array}$} & \multirow{2}{*}{$\begin{array}{c}\text { below } 20 \\
\text { yrs }\end{array}$} & 2 & 0 & 0 & 2 \\
\hline & & & $100.0 \%$ & $0.0 \%$ & $0.0 \%$ & $100.0 \%$ \\
\hline & & \multirow{2}{*}{$21-30 \mathrm{yrs}$} & 26 & 1 & 1 & 28 \\
\hline & & & $92.8 \%$ & $3.6 \%$ & $3.6 \%$ & $100.0 \%$ \\
\hline & & \multirow{2}{*}{$31-40 \mathrm{yrs}$} & 28 & 5 & 6 & 39 \\
\hline & & & $71.8 \%$ & $12.8 \%$ & $15.4 \%$ & $100.0 \%$ \\
\hline & & \multirow{2}{*}{$41-50$ yrs } & 12 & 2 & 1 & 15 \\
\hline & & & $80.0 \%$ & $13.3 \%$ & $6.7 \%$ & $100.0 \%$ \\
\hline & & \multirow{2}{*}{$51-60 \mathrm{yrs}$} & 10 & 7 & 2 & 19 \\
\hline & & & $52.7 \%$ & $36.8 \%$ & $10.5 \%$ & $100.0 \%$ \\
\hline & & \multirow{2}{*}{ over 61 yrs } & 2 & 0 & 1 & 3 \\
\hline & & & $66.7 \%$ & $0.0 \%$ & $33.3 \%$ & $100.0 \%$ \\
\hline \multirow{16}{*}{$\begin{array}{l}\text { Centro } \\
\text { Outpatient } \\
\text { Clinic }^{* *}\end{array}$} & \multirow{2}{*}{\multicolumn{2}{|c|}{ Total }} & 80 & 15 & 11 & 106 \\
\hline & & & $75.4 \%$ & $14.2 \%$ & $10.4 \%$ & $100.0 \%$ \\
\hline & \multirow{14}{*}{$\begin{array}{l}\text { Age } \\
\text { group: }\end{array}$} & below 20 & 7 & 1 & 2 & 10 \\
\hline & & yrs & $70.0 \%$ & $10.0 \%$ & $20.0 \%$ & $100.0 \%$ \\
\hline & & \multirow{2}{*}{$21-30 \mathrm{yrs}$} & 56 & 2 & 0 & 58 \\
\hline & & & $96.6 \%$ & $3.4 \%$ & $0.0 \%$ & $100.0 \%$ \\
\hline & & \multirow{2}{*}{$31-40 \mathrm{yrs}$} & 37 & 7 & 0 & 44 \\
\hline & & & $84.1 \%$ & $15.9 \%$ & $0.0 \%$ & $100.0 \%$ \\
\hline & & \multirow{2}{*}{$41-50 \mathrm{yrs}$} & 34 & 4 & 1 & 39 \\
\hline & & & $87.1 \%$ & $10.3 \%$ & $2.6 \%$ & $100.0 \%$ \\
\hline & & \multirow{2}{*}{$51-60 \mathrm{yrs}$} & 23 & 4 & 0 & 27 \\
\hline & & & $85.2 \%$ & $14.8 \%$ & $0.0 \%$ & $100.0 \%$ \\
\hline & & \multirow{2}{*}{ over 61 yrs } & 5 & 0 & 0 & 5 \\
\hline & & & $100.0 \%$ & $0.0 \%$ & $0.0 \%$ & $100.0 \%$ \\
\hline & & \multirow{2}{*}{ Total } & 162 & 18 & 3 & 183 \\
\hline & & & $88.6 \%$ & $9.8 \%$ & $1.6 \%$ & $100.0 \%$ \\
\hline
\end{tabular}

${ }^{*} \chi^{2}=16,749 ; \mathrm{p}=0.080 ;{ }^{* *} \chi^{2}=29,223 ; \mathrm{p}=0.001$.

ing to the age groups at both outpatient clinics have been found.

4) Upon arrival of a respondent to the reception desk of the medical establishment, $90.3 \%$ of respondents are registered by means of computer. No apparent differences in the breakdown according to the age groups at both outpatient clinics have been found.

5) $72.4 \%$ of respondents say that they have a choice to telephone and inquire about the time of visit if they have forgotten the visit time or lost the appointment sheet. It is also indicated that reminder notice is given by e-mail or SMS text message sent to the phone. Majority of respondents, constituting percentage $35.3 \%$, who make use of the online registration option belong to the age group between 21 and 40 years.

6) Patients of the "Centro poliklinika" and the Šeškinè outpatient clinics rate information technologies at both clinics better in comparison to the results of the 2010 survey. Furthermore, respondents are increasingly more inclined to make use of information technologies. Furthermore, respondents themselves are increasingly inclined to use information technologies. No apparent differences in the breakdown according to the age groups have been identified.

7) Majority of respondents-242 (46.3\%) out of total 523 of those who responded wish to $\log$ in to the online 
registration system of the outpatient clinic using their personal identification number, because it is more convenient. No apparent differences in the breakdown according to the age groups have been identified.

\section{REFERENCES}

[1] 22 February 2010 Order No. V-151 (2010) "Re approval of the programme of the Lithuanian e-health system development for 2009-2015" of the Minister of Health of the Republic of Lithuania. Official Gazette, 2010 Issue 23-1079.

[2] 18 June 2010 Order (2010) "Re approval of the roadmap for implementation of the e-health system development programme for the years 2009-2015" of the Minister of Health of the Republic of Lithuania. Official Gazette, 2010 Issue 74-3763.

[3] Hariharan, S. and Dey, P.K. (2010) A comprehensive approach to quality management of intensive care services. International Journal of Health Care Quality Assurance, 23, 287-300. http://dx.doi.org/10.1108/09526861011029352

[4] Robeznieks, A. (2011) CMS plans IT upgrade to handle growing demands. Modern Healthcare, 41, 32.

[5] Tattersall, A. (2011) International perspectives and initiatives. Health Information and Libraries Journal, 28, 226229. http://dx.doi.org/10.1111/j.1471-1842.2011.00945.x

[6] Lustig, M. (2012) Health care and TEM managing costs of fixed and mobile communications. Healthcare Financial Management, 66, 76-78.

[7] Williams, J. (2012) The value of mobile apps in health care. Healthcare Financial Management, 66, 96-101.
[8] Wagner, K. (2012) 5 ways to provide more connected care. Healthcare Financial Management, 66, 40.

[9] Simon, S.R., Kaushal, R., Jenter, C.A., Volk, L.A., Burdick, E., Poon, E.G., Tumolo, A.Z., Tripahi, M. and Bates, D.W. (2008) Readiness for electronic health records: Comparison of characteristics of practices in a collaborative with the remainder of Massachusetts. Informatics in Primary Care, 16, 129-137.

[10] Andreassen, H.K., Bujnowska-Fedak, M.M., Chronaki, C.E., Dumitru, R.C., Pudule, I., Santana, S., Voss, H. and Wynn, R. (2007) European citizens' use of E-health services: A study of seven countries. BMC Public Health, 7, 53. http://dx.doi.org/10.1186/1471-2458-7-53

[11] Tse, M.M., Choi, K.C. and Leung, R.S. (2008) E-health for older people: The use of technology in health promotion. CyberPsychology \& Behavior, 11, 475-479. http://dx.doi.org/10.1089/cpb.2007.0151

[12] Juodaitè-Račkauskienè, A. (2008) Preparedness of medical staff and patients for implementation of information technologies in outpatient and ambulatory healthcare facilities. Doctoral Dissertation, Biomedical Sciences (10B), Public Health, Vilnius University, Vilnius.

[13] Štaras, K. (2011) Impact of information technologies on the efficiency of operation of healthcare facilities: Analysis, estimates, effectiveness. Doctoral Dissertation, Mykolas Romeris University, Vilnius.

[14] Kairys, J., Juodaitè-Račkauskienė, A., Štaras, K., Čepanauskienè, R. and Čepulis, R. (2011) The patients' opinion on the use of information technologies at the Seškine Outpatient Clinic and "Centro poliklinika" Outpatient Clinic of the city of Vilnius according to the age of patients. Medical Theory and Practice, 17, 55-64. 